\title{
Developmental differences in the encoding of spatial-orientation information
}

\author{
DANIEL W. KEE \\ California State University, Fullerton, California \\ and \\ LYNDA G. HELFEND \\ National Jewish Hospital/National Asthma Center, Denver, Colorado
}

\begin{abstract}
Wickens's (1970) release-from-proactive-interference procedure was used to estimate developmental differences in the encoding of spatial-orientation information from pictorial stimuli. Forty subjects from each of three grade levels-first grade, sixth grade, and college-participated in the study. Results indicated proactive interference buildup for all grades; however, proactive-interference release was suggested only for the sixth-grade and college subjects. The results are discussed in terms of Hasher and Zacks's (1979) views concerning automatic encoding of spatial information from stimuli.
\end{abstract}

The present study was prompted by Hasher and Zacks's (1979) suggestions that spatial information is encoded automatically from stimuli and that developmental changes in this kind of encoding should be minimal. Partial support for this view was provided in a recent study by Park and James (1983), who found that children in grades one, three, and six demonstrated abovechance incidental memory for the spatial location of items. In contrast with Hasher and Zacks's suggestion, however, age differences were detected: Older children showed better incidental spatial-position memory than did younger children.

This study provides an additional appraisal of developmental differences in the encoding of spatial information. Spatial attributes such as position (e.g., Mandler, Seegmiller, \& Day, 1977; Park \& James, 1983) and shape (Hale \& Morgan, 1973; Yussen, Levin, DeRosa, \& Ghatala, 1976) have been studied frequently. However, little evidence about children's encoding of spatialorientation information from stimuli can be gleaned from the literature. Piaget and Inhelder (1965) reported that the acquisition of horizontal and vertical concepts occurs sometime after the age of 8 or 9 years (also see Brainerd, 1978). This finding suggests that the assessment of spatial-orientation encoding offers an excellent test of Hasher and Zacks's (1979) developmental-invariance hypothesis of spatial-attribute encoding. Thus, in the present study, the encoding of spatial-orientation infor-

The authors thank the children and staff of the participating elementary schools of the Los Angeles Unified School District. Appreciation is also expressed to Pat Worden for her helpful comments and careful reading of a draft of this paper. Reprint requests should be addressed to: D. W. Kee, Department of Psychology, California State University, Fullerton, California 92634. mation about pictorial stimuli was estimated using the release-from-proactive-interference (PI) procedure developed by Wickens (1970). The Wickens procedure was selected because it is believed to measure a kind of automatic encoding; that is, the subject's encoding of stimulus-attribute information occurs without intention or conscious awareness (see Wickens, 1970). An important methodological consideration in this study was the selection of stimulus objects that were not associated with typical or characteristic orientations. Because the spatial-orientation dimension was equally arbitrary for all the stimuli, orientation could be manipulated freely, without regard to violation of standard positions of the objects used.

\section{METHOD}

\section{Design and Subjects}

The design of the experiment consisted of a 3 (grade: first grade vs. sixth grade vs. college) $\mathrm{x} 2$ (condition: control vs. shift) x 2 (orientation: horizontal vs. vertical) x 5 (trial: Trial 1 to Trial 5) factorial. Forty students from each of three grade levels-first grade (modal age $=6$ years), sixth grade (modal age $=11$ years), and college (modal age $=18$ years) - participated in the study. The children attended schools serving a middlesocioeconomic-status white community, and the adults were drawn from a university subject pool.

\section{Materials and Procedures}

The materials consisted of 15 black-on-white line drawings of common objects (feather, bullet, oar, paintbrush, hatpin, pencil, match, log, screw, safety pin, key, nail, knife, bat, and hammer). These objects were homogeneous as to shape and were clearly recognizable in either vertical or horizontal depiction. Each drawing was mounted individually on a $10 \times 10 \mathrm{~cm}$ piece of cardboard. During the experiment, a unique set of triads, yoked across the factors of grade level, condition, and trials, was constructed for each subject. Triad membership was determined 
by a random selection (without replacement) of items from the list. Triad membership was constrained such that items did not share an obvious association or common first letters with the verbal labels.

The subjects were tested individually. Each trial in the task involved the sequential presentation of each member of the triad at a $2-\mathrm{sec}$ rate. As each item was presented, the experimenter labeled the picture and the subject repeated the label aloud. A 15sec filled retention interval involving a simple numerical rating task (see Kee \& Helfend, 1977) followed the presentation of the triad. During the $10-\mathrm{sec}$ recall interval that immediately followed the retention interval, the child was asked to recall the triad. Each subject received five such trials. Stimulus presentation was manual and was timed with a stopwatch.

Subjects from each grade were assigned randomly to either a control or a shift condition. Control-condition subjects received five trials of triads in which the objects were depicted in the same spatial orientation (vertical or horizontal). Shift-condition subjects received four trials of triads in which the items were depicted in one spatial orientation and a fifth trial in which the orientation of the objects was changed. The orientation of the objects was counterbalanced across conditions, and the triads presented to the shift-condition subjects on Trial 5 were identical to those presented to the subjects in the respective yoked control condition.

\section{RESULTS}

The dependent variable selected for analysis was the number of correct responses given by the subjects on each test trial. Figure 1 presents the results for this variable as a function of grade, condition, and trial. Analysis of performance on Trials 14 provides evidence of PI buildup. A significant trial effect was observed, which indicates a decline in recall between Trial 1 and Trial 4 $[F(3,342)=71.00, p<.01]$ This main effect was qualified by a significant grade $x$ trial interaction $[F(6,342)=$ $3.54, \mathrm{p}<.01]$, which suggests that this decline over

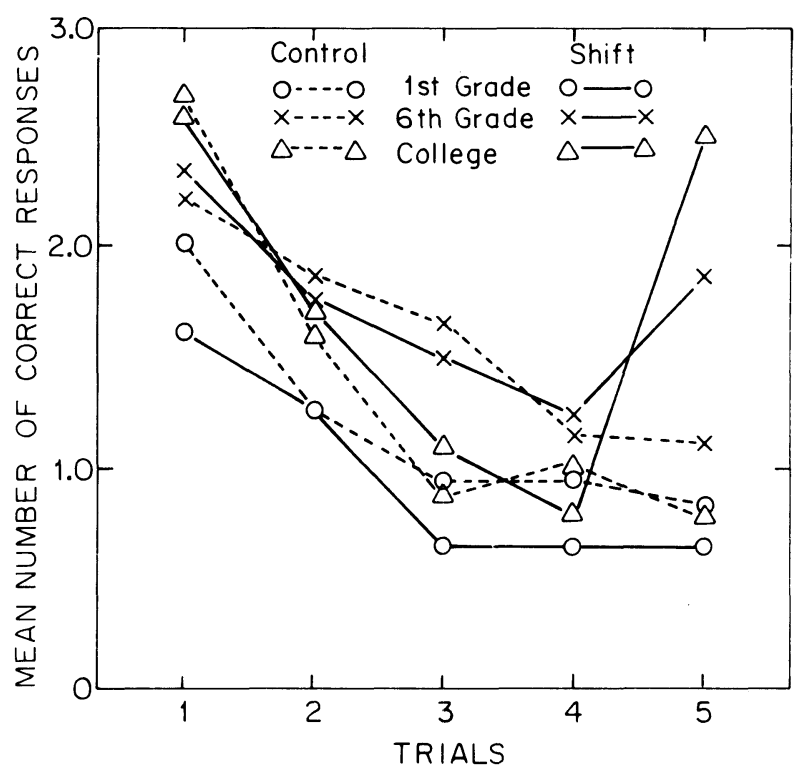

Figure 1. Mean number of correct responses as a function of condition, trial, and grade. trials was largest for the college subjects (Trial 1 to Trial 4 difference $=1.73$ items), followed by the sixthgrade (Trial 1 to Trial 4 difference $=1.08$ ) and the firstgrade (Trial 1 to Trial 4 difference $=1.00$ ) subjects. A simple-effects analysis indicated significant trial effects within each of the grade levels, which implicates PI buildup. A final significant effect observed in the Trials 1.4 analysis was for grade $[F(2,114)=19.21, p<.01]$. Pairwise comparisons $(a=.05)$ indicated that the recall performance of the first-grade subjects was lower than that of the sixth-grade and college subjects and that the performance of the sixth-grade subjects did not differ from that of the college subjects.

Release from PI is implicated if a performance improvement in the shift condition and a performance decline or no change in performance in the control condition occur between Trial 4 and Trial 5 (see Wickens, Moody, \& Dow, 1981, for a recent discussion of the locus of this release-from-PI effect). An analysis of variance for Trial 4 performance versus Trial 5 performance indicated significant condition $\mathrm{x}$ trial $[\mathrm{F}(1,114)=20.38]$ and grade $\mathrm{x}$ condition $\mathrm{x}$ trial $[\mathrm{F}(2,114)=7.11]$ interactions ( $\mathrm{ps}<.01)$. Descriptively, it appears that PI release was evident for the sixth-grade and college subjects, but not for the first-grade subjects. Within-grade analyses indicated a significant condition $\mathrm{x}$ trial interaction for the college group $[\mathrm{F}(1,38)=45.91, \mathrm{p}<.01]$, but not for the sixth-grade $[\mathrm{F}(1,38)=2.30, \mathrm{p}>.10]$ or the firstgrade $(F<1)$ group. Because of the release from PI suggested in Figure 1 for the sixth-grade subjects, two additional analyses were conducted for that age group. On Trial 5, a recall difference favoring the shift condition over the control condition was detected, and higher recall on Trial 5 than on Trial 4 was observed in the shift condition $(\mathrm{ps}<.05)$. Both of these significant results implicate reliable PI release within the sixth-grade group. The Trial 4 versus the Trial 5 analysis also indicated significant effects for grade, condition, and grade $\mathrm{x}$ condition (all ps $<.05$ ). These effects, however, did not serve to qualify conclusions reached about developmental differences in release from PI.

\section{DISCUSSION}

The results of this study suggest automatic encoding of spatialorientation information by college and sixth-grade subjects. Calculation of percentage of PI release according to the formula suggested by Wickens (1970) indicates clearly that the college group was associated with more PI release-hence the more salient encoding of spatial-orientation information relative to that of sixth-grade subjects (percentage of PI release: college subjects $=$ $89 \%$; sixth-grade subjects $=68 \%$ ). The absence of PI release for the first-grade subjects suggests that, under the present task condition, spatial-orientation information may not be automatically extracted. The task conditions used in this study are similar to procedures we have used in previous release-from-PI studies that have documented both semantic and structural encoding in children of ages comparable to those in this study (see Kee \& Helfend, 1977 , and Kee \& DeHaven, Note 1). Thus, it is unlikely that our procedures are insensitive, per se, to attribute encoding in young children. One possibility, however, is that the $2-\mathrm{sec}$ exposure of 
triad members may not have been sufficient for the younger children to abstract the spatial-orientation information from the stimuli, because young children may have less efficient visual processing (see Hoving, Spencer, Robb, \& Schulte, 1978). Alternatively, retrieval factors could be partially responsible for the absence of PI release in the first-grade subjects.

The observed developmental increase in release from PI may reflect age-related changes in strategic encoding. That is, older subjects may be more likely to notice the spatial orientation of objects and may deliberately encode this information. Informal postexperimental questioning of subjects, however, did not provide any evidence to support this view. It may be that younger children can be prompted to encode spatial-orientation information from pictorial stimuli if task conditions are arranged appropriately. Furthermore, automatic encoding of spatial-orientation information may be more likely for objects that are associated with typical or canonical orientations. These possibilities certainly should be explored in future work.

Recall that Hasher and Zacks (1979) suggested that spatial information may be encoded automatically. The present study indicated clearly that both older children and adults appear to automatically encode the spatial orientation of pictorial stimulus items. Contrary to Hasher and Zacks's contention that developmental differences should be minimal in such automatic encoding, evidence for spatial-orientation encoding in younger (firstgrade) children was not provided. Finally, it will be recalled that children's acquisition of the concepts of horizontal and vertical occurs sometime after the age of 8 or 9 years (Piaget \& Inhelder, 1965). Although the acquisition of these concepts has been studied in tasks that were quite different from the memory procedures used in this study, the similarity of the developmental shifts observed across tasks suggests that children's ability to encode spatial-orientation information may reflect more general age-related changes in cognitive development.

\section{REFERENCE NOTE}

1. Kee, D. W., \& DeHaven, D. T. Developmental changes in semantic and structural encoding. Paper presented at the meeting of the Western Psychological Association, Los Angeles, April 1981.

\section{REFERENCES}

Brainerd, C. J. Piaget's theory of intelligence. Englewood Cliffs, Prentice-Hall, 1978.

Hale, G. A., \& Morgan, J. S. Developmental trends in children's component selection. Journal of Experimental Child Psychology, 1973, 15, 302-314.

HAsher, L., \& ZAcks, R. T. Automatic and effortful processing in memory. Journal of Experimental Psychology: General, 1979, 108, 356-388.

Hoving, K. L., Spencer, T., Robb, K. Y., \& Schulte, D. Developmental changes in visual information processing. In P. A. Ornstein (Ed.), Memory development in children. Hillsdale, N.J: Erlbaum, 1978.

KeE, D. W., \& Helfend, L. Assessment of taxonomic encoding categories in different populations. Journal of Educational Psychology, 1977, 69, 344-348.

Mandler, J. N., Seegmiller, D., \& DAY, J. On the coding of spatial information. Memory \& Cognition, 1977, 5, 10-16.

PARK, D. C., \& James, C. Q. Effect of encoding instructions on children's spatial and color memory: Is there evidence for automaticity? Child Development, 1983, 54, 61-68.

Piaget, J., \& Inhelder, B. The child's conception of space. New York: Norton, 1965.

Wickens, D. D. Encoding categories of words: An empirical approach to meaning. Psychological Review, 1970, 77, 1-15.

Wickens, D. D., Moody, M. J., \& Dow, R. The nature and timing of the retrieval process and of interference effects. Journal of Experimental Psychology: General, 1981, 110, 1-20.

Yussen, S. R., Levin, J. R., DeRosa, T. M., \& Ghatala, E. S. Individual differences in young children's recall and clustering of pictures. Contemporary Educational Psychology, 1976, 1, 170-179.

(Manuscript received for publication June 1, 1983.) 